\title{
On Validity and Improvement Strategies of Proposition in Putonghua Test
}

\author{
Huiling Sun \\ Weinan normal University, Shaanxi, China \\ Wszn30@126.com
}

Keywords: Putonghua test; Propositional talk; Validity; Man-machine dialogue

\begin{abstract}
In the Putonghua Test, the proposition is crucial in determining the subjects' Putonghua level. But the design of proposition is defectiveness .the subjects are in front of the computer without communication object and not in the communication field, just one-way talking for three minutes. Such talk is very few in daily life and also lacks practical communicative functions. The method is not consistent with the purposes and can't really reflect the participants' Putonghua level of speaking. This part should be improved in the computer environment to create a way of dialogue, and each topic should be designed into smaller topics, and each of them would be elaborate designed focusing on pronunciation and vocabulary, grammar and fluency in man-machine dialogue mode. Thus the whole testing process is controllable and close to the natural dialogue avoiding the back draft, rigid tone, and poor oral and so on.
\end{abstract}

\section{Introduction}

It is important to popularize Putonghua in China, which has been proved by many experts and has formed a consensus in the whole society. As a powerful means to popularize Putonghua, the significance of Putonghua testing is particularly important and far-reaching. The proficiency test of Putonghua is a powerful means to popularize Putonghua, and is a major measure to make the work of Putonghua into a new stage. It has played an active role in promoting the promotion of Putonghua in the direction of institutionalization, standardization and scientific.

The "Outline of the Putonghua Proficiency Test" (Ministry of education, The National Language Committee issued document No. [2003]2) provides the name, nature, method, content and scope of the test, the composition and grading of test papers, and the determination of the mandarin level of the examinees. Among them, the "composition and scoring of the test paper" detailed the test questions and their respective scores:

Read monosyllabic words (100 syllables, not including soft, R-coloring syllable) with a limit of 3.5 minutes, 10 points.

Read polysyllabic words (100 syllables), 2.5 minutes, and 20 points.

Read the passage ( 1 article, 400 syllables), 4 minutes, and 30 points.

Proposition speech, 3 minutes, and 40 points.

\section{Problems in the Test of "Propositional Talk"}

In this sense, "propositional talk" has the highest score in the whole test, and is the most important part in the test scores, which is very important for determining the Putonghua level of the tested. And speaking is the most basic expression of spoken language, and it can also reflect the level of a person's Mandarin. Therefore, it is listed as an important part of the Putonghua proficiency test and it is reasonable to take the largest share of the total score. So it's the most important thing to study. Most of the places are now starting to use computer aided Mandarin proficiency tests. The first three problems can now be measured by computers, and the technology is relatively mature. Compared with the manual, the score is also more objective. It overcomes the indeterminate components such as test fatigue and individual subjective factors during the test of test controller. And the same system is used throughout the country, which is more fair and reasonable for the people to be measured. But the "propositional talk " part is still redistributed by the computer after 
being tested by the testers. Because of the fact that it is not on-site testing, some technical factors and non-technical factors make this part of test validity still need to be improved.

The influence of technology and equipment .The "propositional talk " section of the test was recorded by a computer. In this process, some of the voice defects of the tested subject were covered due to technical reasons such as recording equipment, hearing equipment and transmission equipment. Even some of the utterances have affected the tester's determination of the true standard of Putonghua of the tested subject because of the broken machine.

The influence of time, task and other distribution factors. When this part of the recording task is assigned to the tester, the tester is completed within a certain time, and the location is not limited. This requires that the testers should be able to allocate the time reasonably and assign the test tasks scientifically to ensure that the whole test is basically objective and impartial, and the standard is unified. But in the actual testing work, testers are usually part-time. They also have heavy workload and scientific research tasks. And now the test pay is relatively low, and testers' test enthusiasm is not high. Especially in some normal colleges and universities, the test task is very large, and the test time is very urgent. In this case, the tester sometimes only has to be able to complete the task on time, and it is difficult to ensure that the test results are good.

The influence of the tester's own state .Finally, since the test work is completed in a period of time, there is no guarantee that the tester will maintain a constant state during each power-on test. Therefore, in addition to the original man-made subjective factors, the objective state will inevitably have ups and downs, thus affecting the stability and effectiveness, objective and fair of this part of the test.

These will ultimately affect the overall score of the test target and the standard of Mandarin. Therefore, we need to do a careful study in this area.

\section{The "Propositional Talk" Itself Needs to Be Improved}

In addition to these factors, the most important thing is that the test form of "propositional talk" itself needs to be improved, and it needs to be fundamentally improved. In the sixth part of the "Guidelines for Putonghua Proficiency Test" in the national instruction book of Putonghua proficiency test, there are briefly 30 topics for the proficiency test of Putonghua. There are two explanations for it:

1. 30 topics for Putonghua proficiency test fourth - propositional talk test to use.

2. 30 topics is only the provisions of the scope of the topic, does not specify the content of the topic.

These 30 propositions are: My wish, My study life, My respectable person, My favorite animal (or plant), Childhood memories, My favorite occupation, Unforgettable trip, My friend, My favorite Literary (or other) art forms, Talk about health, My amateur life, My favorite season (or weather), My understanding of mandarin, Dress, My holiday life, My path to growth, The development of science and technology and social life, The customs of I know, I and sports, My hometown (or familiar place), Talk about food, My favorite festival, My group (schools, agencies, companies, etc.), Talk about social ethics (or professional ethics), Talk on personal accomplishment, My favorite celebrities (or other celebrities), My favorite books and periodicals, talk about my understanding of environmental protection, The place I aspire to, The feeling of shopping (consumption) and so on. It should be said that these 30 topics basically cover every person's life, study and work in many aspects, or account or comment. In actual test, they are also two choices, which will not let the tested have nothing to say.

But this part is called "propositional talk". The test is also "the level of Putonghua in the case of no word dependence". The key is to measure the degree of pronunciation standard, the degree of vocabulary grammar, and the degree of natural fluency. This is the purpose of the design of "propositional talk" in the syllabus of the proficiency test of Putonghua. But in practice, it is often the ability of oral composition rather than speaking ability. Because most of the words in daily life have a certain communicative purpose, the topic is also very free, can be two-way communication, and can also be multi - directional communication. Even if it is a designated topic, there are certain 
objects of communication. But the "propositional talk" is a one-way manner, that is to say the subjects no communication object, not in the communication field, is entirely a person talking, and have the time limit, the limit of topic. And in actual test, though "only the scope of the topic is specified, the specific content of the topic is not specified", but it is unavoidable that the specific content of the topic affects the result of the tested person. And because the topic is a one-way conversation, the time is no less than three minutes, so that a topic can be talked for three minutes, and at medium speed, the total is about 500-700 words. The 500-700 word one-way speech is rarely used in daily life, seldom used, and lacks practical communication function. Such testing methods are not consistent with the purpose of the test, and thus cannot truly reflect the true level of spoken Mandarin by the subjects. On the contrary, because it is a one-way speech, there is a possibility that the mandarin level which does not match with the real voice of the subject may be caused, because the subject is fully prepared or not, or whether the subject is familiar or not. Because of computer auxiliary test, lack of testers intervention, the subjects are more likely to occur in script, stiff, colloquial and some problems, and then the test can't truth fully reflect the actual pronunciation of the subjects.

\section{The Reform of the "Propositional Talk"}

Therefore, the part of "propositional talk" needs to be reformed in the test of Putonghua level. The purpose of the test remains unchanged. It is still testing the level of Putonghua in the daily life of the tested subjects. The key test is still "the standard of speech, the degree of vocabulary grammar, the natural fluency", but the content of the test can be adjusted and the testing method can be changed.

In the past, when the auxiliary test of computer was not present, the test staff could interfere with the back draft of the tested person, and also guide the subjects to speak. And the testers are also able to communicate after all, the object of the exchange - - people, testers can judge their level of communication through the exchange. After all, the subjects are also able to communicate the object - testers, and the testers through such communication are to judge the subject's level of speaking. However, after the advent of computer-aided testing, the subject was confronted with a machine, lacking the object of communication, not being in the communication field, and it was indeed defective through the method to testing the level of the subject. It is also unrealistic for the centrally organized testers to test this part of the field. For example, the problem of the reorganizing of the tested person, the problem of the test site, and the problem of the whole test cost, etc., make this method lack practicality. So this part of the test improvement should be the idea of creating a dialogue in the computer environment. For example, design a number of small topics on each topic, and each topic is carefully designed to focus on the degree of phonetic standard, the degree of vocabulary grammar, and the degree of natural fluency. The subjects were allowed to choose between five and ten of them. Later with the development of computer technology, also can design the man-machine dialogue mode, make the whole testing process can be controlled, and close to the natural dialogue, while avoiding the subjects' script, or because of inadequate preparation it affects the assessment of the real voice of the tested person. This will make Putonghua testing work more scientific, just and objective, and will also effectively promote the improvement of the mandarin level of the whole society.

\section{Conclusion}

In a word, the proficiency test of Putonghua is a very important work. Among the four oral test questions currently used, the fourth questions "propositional talk " is the most important, which accounts for the most and reflects the true voice of the tested person. Now, there are some problems in the contents and methods of this problem. If we do not solve these problems, it will affect the level of Putonghua in this part of the test, and it will also affect the objective and impartiality of the test of the whole Putonghua level.

For the test validity and tactics of "propositional talk "in Putonghua test, This paper made some 
argumentation and research, but the research is still inadequate, also cannot completely solve the problem, still need more scholars make communication study and research in this area. Later with the continuous development of human science and technology, computer aided technology in the test will also get development, these problems should be improved, and mandarin level test work will be more perfect.

\section{Acknowledgements}

The subject of Education Science in Shaanxi "Research on the innovation of the teaching mode of national education in the E era" (SGH0902206)

\section{References}

[1] The implementation outline of Putonghua proficiency test [Z]. Beijing: business printing, 2004.

[2] Yao Xishuang et al. Introduction to test of Putonghua proficiency [M]. Beijing: education press, 2011.

[3] Wang Guibo. Mandarin training and testing course [M]. Beijing: education press, 2012.

[4] Wang Jinghua, Yin Jianguo. Mandarin oral communication [M]. Beijing: Beijing normal university press, 2011.

[5] Cui Mei, Zhou yun. Mandarin proficiency test training course [M]. Beijing: Beijing normal university press, 2013.

[6] Li Yacui. Research on mandarin education [M]. Beijing: central compilation press, 2011. 